\title{
Model Research on the Influence of Bearing Preload Change on the Frequency and Form of Natural Vibrations of the Spindle System
}

\author{
Paweł Turek ${ }^{*}$, Wacław Skoczyński ${ }^{1}$ \\ 1 Wroclaw University of Science and Technology, Department of Machine Tools and Mechanical Technologies, \\ ul. Lukasiewicza 5, Building B-4, Wrocław, Poland \\ * Corresponding author's e-mail: pawel.turek@pwr.edu.pl
}

\begin{abstract}
The article presents an FEM model of the spindle system, in which angular contact ball bearings with active preload control are used. This model allowed determining the frequency and form of natural vibrations of the system. The model was prepared using the Abaqus programming environment. Various bearing preload states were adopted during the tests. It was shown that the spindle system is sensitive to the changes in the stiffness of bearing supports. The tests conducted using models were then verified on a real stand. First of all, using the external excitation from an electromagnetic exciter, the frequency range of resonance vibrations of the spindle system was determined. Then, the amplitude - frequency characteristics of the tested spindle were determined at various bearing preload values. A general operation scheme of the control system for the active change of the preload value of the angular contact ball bearings during the work of the spindle system was proposed.
\end{abstract}

Keywords: natural frequencies, active preload bearings, spindle vibration forms, FEM model

\section{INTRODUCTION}

Modern machine tools often use electric spindles as the main drive. Angular contact ball bearings are usually used as their bearings, which have the ability to transfer both radial and axial forces [15]. These types of bearings require the correct preload for proper operation, which significantly affects the dynamic properties of the spindle and the entire machine tool. The correct preload [4] of a bearing system is also important when determining the frequency and form of natural vibrations of the spindle system, and it also affects its amplitude-frequency characteristics [7]. From a model point of view, the entire spindle can be simplified to a shaft supported on two supports, which allows modelling such a system easily [16]. In the case of mechanical structures such as bars, beams or shafts, one should also remember about resonance vibrations, which may lead to a decrease in durability or damage to a given type of structure. Self-excited vibrations are also particularly destructive to machine tools [24].
Each machine tool spindle is subjected to both kinematic and force excitations during operation (mainly associated with the cutting process). An example of the simplest periodically variable load is harmonic excitation. It is described in the form of the function:

$$
y(t)=A \sin \left(\omega t+\varphi_{0}\right)
$$

where: $A$ - vibration amplitude, $\omega$ - angular frequency of vibrations, $\varphi_{0}-$ phase shift angle, $t$ - time.

Resonance vibrations of considerable amplitude can be caused by a relatively small periodically acting force. For this reason, machine operation with excitation forces close to these frequencies should be avoided. In dynamic systems with many degrees of freedom, there are many natural vibration frequencies, and resonance may occur for each of them. The highest amplitude resonance vibrations occur at the lowest frequencies, often in the working area of the spindle. Therefore, in order to properly design a spindle, it is necessary to know the area of occurrence of these frequencies the value of which changes with the 
bearing preload. The purpose of this paper was to determine the possibility of changing the bearing stiffness in the spindle model under operating conditions and to determine the impact of this change on the system's resonance frequencies.

From a model point of view, the spindle assembly is a system that consists of a spring beam (spindle) and spring supports (bearings). Two types of natural vibrations and their accompanying forms occur in this type of structures. The first type is dominated by transverse vibrations of the spindle with small amplitudes of vibrations in bearing supports. In the second one, the spindle swaying is dominant, during which the spindle behaves almost like a rigid body, large vibration amplitudes occur in bearings. The article puts the main emphasis on the latter type of natural vibrations, because the elastic properties of bearings determine their frequencies and amplitudes. In the case of spindles with angular contact ball bearings, the frequency and amplitude of natural vibrations is related to the value of the preload of these bearings. The stiffness of bearings increases with the preload, which usually affects the decrease of the spindle's natural vibration amplitude and the change of the frequency of these vibrations. The presented test results are to show that it is possible to use a system of adjusting the stiffness of bearing supports during spindle operation and how active systems positively affect the properties of the spindle system.

\section{OVERVIEW OF SELECTED MODELS}

Nowadays, developing models of machine tool spindles is a common solution. On the basis of theoretical knowledge presented for example in $[3,8,9]$, the model is made of single elements (e.g. bearings, slides, body) and the whole machine. This type of action is necessary when developing machine prototypes to correctly determine the properties of a given machine at the design stage. The use of the model is also checked at the time of modernization and improvement of the existing structures as well as allows predicting the behaviour of the machine under specific operating conditions [2].

In the literature various types of models can be found, owing to which a given area of the machine properties can be described. Static models [31] describing the load distribution and stiffness of e.g. machine body can be distinguished. In dynamic models $[10,22]$ for example, forces, moments, temporary loads on drives are determined, e.g. related to the cutting process. A lot of attention is paid to the thermal phenomena in modelling [16]. The dimensional and shape change of machine tool components and its negative impact on machining accuracy are analyzed. On the basis of the model, the performance of the cooling system can be predicted as well.

The benefits of using models for machine tool testing mean that their popularity is constantly growing. However, in the case of more and more modern machines, the use of only analytical models $[18,32]$ is an inefficient and very time-consuming technique.

The continuous development of computers, increasing their power and computing efficiency means that quite often models are developed using the FEM (finite element method) technique for simulating the behaviour of machine tool components. It is based on the division of the modelled object into finite elements. For these elements, the results are approximated using specific functions, and calculations are carried out only at nodal points. This technique can be encountered in bearing models for determining their stiffness as well as static and dynamic properties of a complete machine tool spindle [34]. The latest works related to the development of machine tool models based on the FEM technique are focused on the creation of one model describing the entire machine tool, which will allow predicting its behavior under any operating conditions [14]. Such action, however, is currently burdened with many approximations, which often overlook many details related to the main components of the machine tool. One of these main elements is e.g. a spindle, and bearings inside, which often govern its properties.

Despite the continuous development of numerical models using the FEM technique, there is still a problem with the dynamic description of the modeled bearing properties. This problem arises at the junction of the bearing race and the rolling element and is the larger the more accurate the calculations and the higher the spindle speed. Due to the lack of unambiguous information on the ball behavior in the angular contact bearing during its work (determining how the rolling element contacts the outer and inner rings of the bearing), various researchers use different types of simplifications to describe this contact [14, $15,18,29]$. They were presented extensively in 
[25], where the author describes various substitute models and proposes his own concept for the modelling of large bearings. The problem of rolling element/bearing race contact is also found in the case of modelling the frequency and form of spindle's natural vibration. The computer programs using the FEM technique (e.g. Abaqus, Ansys) have a number of limitations that require the use of some type of model simplification. In the presented work, the authors decided to use the Abaqus program, which for the application of frequency analysis is not allowed to define contact between cooperating surfaces. For this reason, the model presented in the FEM article uses simplification to eliminate bearing rolling elements and replace them with a ring element. The authors decided on this type of solution because as presented in the article, it guarantees the correctness of results in a satisfactory time and maintains the correct mapping of the spindle.

\section{APPLICATION OF VARIABLE BEARING PRELOAD IN SPINDLE SYSTEMS}

The problem of proper preload in angular contact ball bearings is widely considered by many researchers around the world $[3,6,13,17,21,27$, $33,35]$. On the basis of many years of experience, they came to the conclusion that the best solution used in machine tool spindles is to use an active bearing preload system. This term denotes many different constructions, examples of which can be found in [28]. The first systems for active tensioning of bearings using piezoelectric elements can be found already in the 1990s [23]. The need to use variable preload conditions of bearings was initially mainly associated with thermal phenomena. Considerations on this subject are presented in [27], and variable preload systems, owing to which the negative effect of temperature on the bearing assembly operation can be limited, are described in $[19,30]$.

With a change in the value of the preload of bearings in the spindle system, its stiffness and the level of natural amplitudes and frequencies change. For this reason, dynamic tests are carried out to correct or change the value of the preload in angular contact bearings. They are related, for example, to the centrifugal force arising in the case of high-speed spindles [5] or variable axial rigidity of the spindle [20]. It should also be remembered that the variable preload also has an effect on changing the bearing life [35]. There are also works in the literature in which the authors deal with the influence of variable preload on the dynamics of e.g. grinding spindles [1], and the frequency of rotation of the spindle [33]. Most of the active systems used are based on piezoelectric [11, 26] or electromagnetic elements [13]. However, it is difficult to find the examples of the use of active preload systems of bearings used to minimise vibration of the machine spindle tip. For this reason, the authors of this work attempted to draw this problem forward. Using the FEM model and the actual system on the test setup, they showed how a change in bearing preload affects the amplitude and natural frequency of the spindle system.

\section{DETERMINATION OF INITIAL ASSUMPTIONS FOR THE FEM MODEL}

The initial analysis of the frequency and forms of natural vibrations of the tested spindle was carried out using the Abaqus program. In order to make these calculations possible during the modelling process, the following simplifications were introduced:

- the model includes a shaft with two substitute rings (bearings on the spindle),

- the inner surfaces of the rings were mounted in the place of bearings and fixed permanently to the shaft using the tie function,

- the C3D8R elements were used in the model,

- the change in preload (stiffness of bearing supports) was modelled by changing the material properties of the substitute rings,

- identical preload was adopted for both replacement rings.

The manufacturer's data used in the tests [38], determine the bearing stiffness for different values of preload force. On the basis of preliminary simulations, the Young's modulus for the replacement ring was determined, the change of which corresponded to the change in the value of the bearing preload. Determination of Young's modulus was as follows. In the first stage, the substitute ring itself was modelled and one of its side surfaces was fixed. A bearing preload force was applied to the other side surface (in this case $60,90,125,200,280,360,430 \mathrm{~N})$. After each simulation, the relative displacement of the side surfaces of the substitute ring was read. The measured displacement value was compared with the catalogue data. Then, the value of Young's 

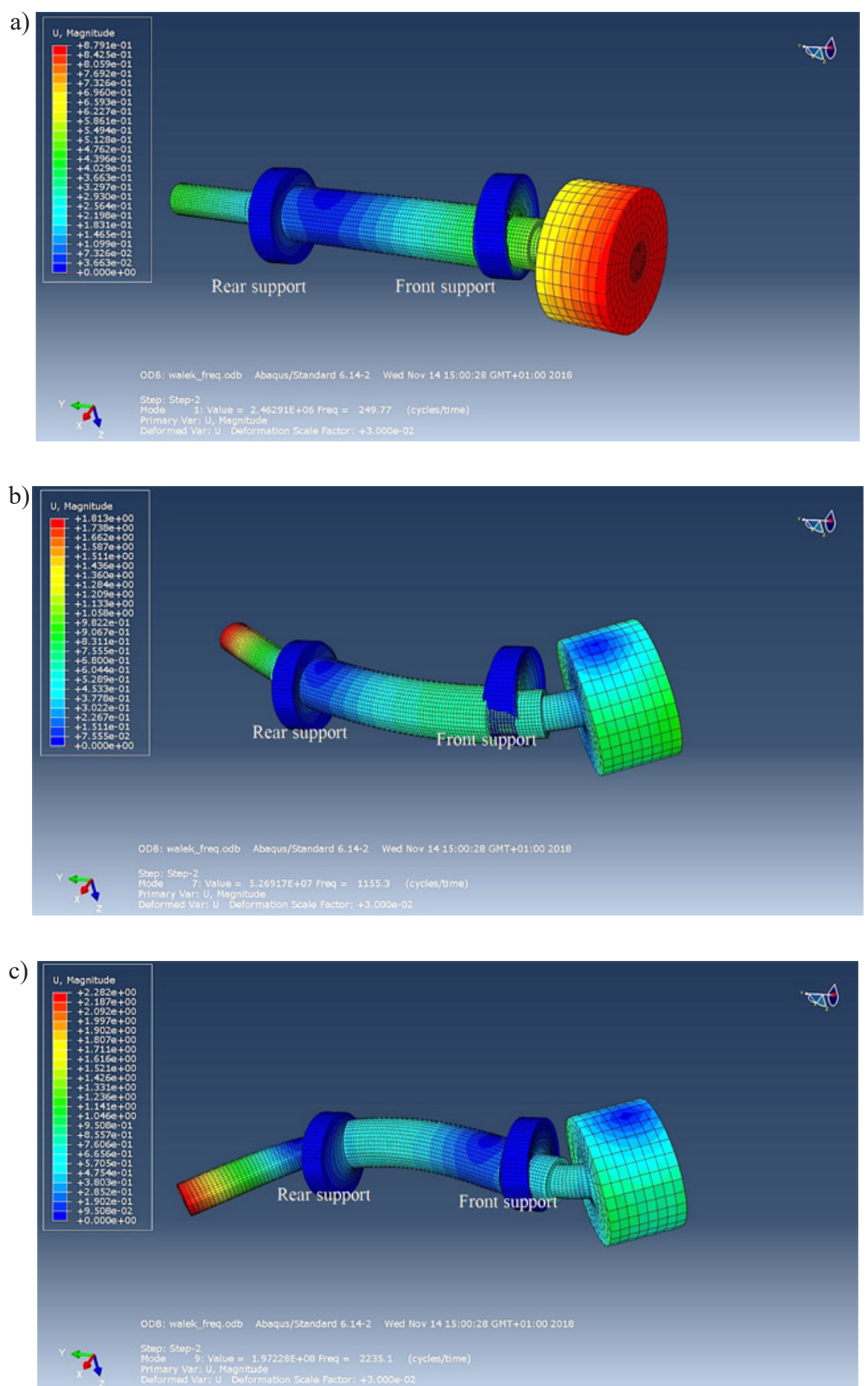

Fig. 1. Relative vibration amplitudes accompanying the first three forms of spindle natural vibration for average bearing preload of $200 \mathrm{~N}$ for frequency: a) $249 \mathrm{~Hz}$, b) $1155 \mathrm{~Hz}$, c) $2235 \mathrm{~Hz}$

modulus was corrected and the simulation calculations were repeated. This stage of the tests was performed until the seven values of Young's modulus were obtained, which ensured a satisfactory adjustment of the substitute ring stiffness to the stiffness of the catalog angular contact ball bearing used in the spindle. Using the seven different values of Young's modulus obtained in this way (corresponding to seven values of the preload force of the bearings) for the replacement rings, a spindle model was developed, which allowed initially estimating the level of several lowest frequencies and forms of natural vibrations. In the spindle model, the weight of the potential tool with a clamping chuck was taken into account and a substitute mass in the cylindrical form was 
Table 1. Comparison of basic natural frequencies for variable bearing preload conditions

\begin{tabular}{|c|c|c|c|c|c|c|c|}
\hline Preload force [N] & 60 & 90 & 125 & 200 & 280 & 360 & 430 \\
\hline $\begin{array}{c}\text { Frequency for the first form } \\
\text { of vibration [Hz] }\end{array}$ & 182.1 & 199.6 & 222.6 & 249 & 283.8 & 311.8 & 333.1 \\
\hline $\begin{array}{c}\text { Frequency for the second form } \\
\text { of vibration [Hz] }\end{array}$ & 1126.5 & 1132.8 & 1142.2 & 1155 & 1175 & 1194.6 & 1211.7 \\
\hline $\begin{array}{c}\text { Frequency for the third form } \\
\text { of vibration [Hz] }\end{array}$ & 2224.8 & 2227 & 2230.4 & 2235 & 2242.4 & 2249.7 & 2256.4 \\
\hline
\end{tabular}

introduced. Figure 1 shows the first three forms of natural vibration of the spindle shaft with replacement rings and the corresponding frequency values for the preload of $200 \mathrm{~N}$.

This type of simulation was carried out for all seven preload values, i.e. the entire range of bearing preload. Because the bearing system cannot work with a zero preload force, the first point was determined at $60 \mathrm{~N}$. The last point was adopted for the preload value specified in the specifications as heavy load $-430 \mathrm{~N}$. Only the three lowest frequencies were taken into account, which corresponded to one translational (associated with the swinging of the spindle on the supports) and two transverse forms of the spindle own vibrations. It was noted that the lowest frequency corresponds to the largest amplitude of the relative displacements between the outer and inner bearing rings. The results of the model tests are presented in Table 1.

On the basis of model tests, the theory that a change in the stiffness of substitute rings causes a change in the basic values of the spindle's natural frequencies was put forth. It can therefore be assumed that when the bearing stiffness changes during spindle operation, these frequencies can be effectively influenced. At the same time, on the basis of the diagram in Fig. 2, it can be seen that the change in the preload value has a much greater impact on the frequencies associated with the translational form of spindle vibrations (first frequency). Then, the spindle shaft behaves like a rigid body, and there are significant amplitudes of vibration displacements of the shaft in the radial direction in the places of support (bearing supports). In order to confirm this theory, experimental tests were conducted on a test setup.

\section{EXPERIMENTAL VERIFICATION OF THE MODEL}

In order to confirm the results obtained on the basis of the FEM model, the measurements of vibration and the behaviour of the spindle model shaft were carried out on a real test setup. Its main element was the individually designed spindle with B7206-CT-PS4-UM angular contact bearings made by FAG, the parameters of which are included in the specifications [38], and a module that allows for changing the preload value of the bearing system without having to disassembly the entire spindle. The bearing spacing, i.e. the distance between the centres of gravity of the rolling elements in the spindle, was determined at 0.154 $\mathrm{m}$. According to the design assumptions, the change of the initial load will take place through the rear support and the angular contact bearings will be assembled in the "O" arrangement. Each bearing support could transmit both radial and axial forces. In order to change the preload, three PSt 150/10/40 VS15 piezo actuators from Piezomechanik GmbH were used (Fig. 3), positioned symmetrically with respect to the spindle axis
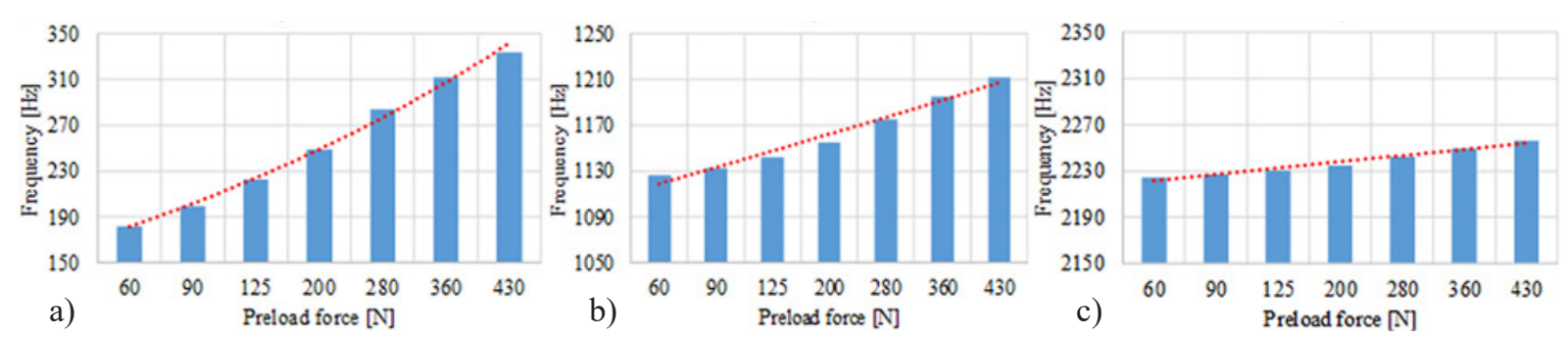

Fig. 2. Comparison of lowest natural frequencies for variable bearing preload conditions for the forms of vibration: a) first, b) second, c) third 


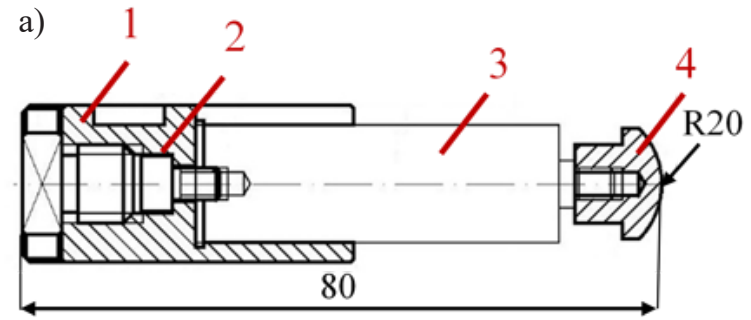

b)

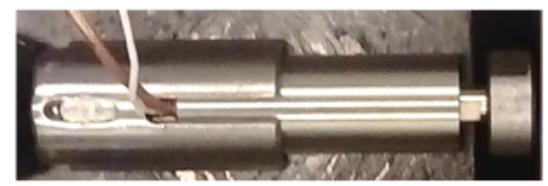

Fig. 3. View of a single piezo actuator PSt 150/10/40 VS15 with mounting sleeve, a) design drawing (1 mounting sleeve, 2 - mounting screw, 3 - piezo actuator, 4 - spherical rounding), b) real component

Table 2. Piezo actuators and power supply parameters $[36,37]$

\begin{tabular}{|l|c|}
\hline PIEZO ACTUATOR TYPE & PSt 150/10/40 VS15 \\
\hline Maximum stroke $[\mu \mathrm{m}]$ & $55 / 40$ \\
\hline Supply voltage $[\mathrm{V}]$ & $-30 /+150$ \\
\hline Piezo actuator length $[\mathrm{mm}]$ & 46 \\
\hline POWER SUPPLY TYPE & SVR $150 / 3$ \\
\hline Voltage signal [V] & $+/-5$ \\
\hline $\begin{array}{l}\text { Number of independent } \\
\text { channels }\end{array}$ & 3 \\
\hline Max. current $[\mathrm{mA}]$ & 60 \\
\hline Actuator connection & $\mathrm{BNC}$ \\
\hline Output voltage $[\mathrm{V}]$ & $-30 /+150$ \\
\hline
\end{tabular}

(Fig. 5). The preload was controlled via a strain gauge module and displacement sensors built-in in each piezo actuator. The piezoactuator and amplifier parameters are summarised in Table 2.

In order to determine the spindle response to various types of excitation under varying operating conditions, it is necessary to prepare an amplitude - frequency characteristic. Due to the computational complexity of the problem, FFT (fast Fourier transform) is used for this type of analysis [24]. There is a theory that every signal can be understood as a superposition of sinusoidal functions at different frequencies. During the measurement, each recorded signal is subject to an error arising at the level of the sensor itself or its recording system. Any disturbance should be effectively eliminated or filtered out during the analysis. The use of FFT analysis due to the lower computational complexity compared to DFT (discrete Fourier transform) provides faster performance. It uses Fourier transform

$$
X(j \omega)=\int_{-\infty}^{+\infty} X(t) e^{-i \omega t} d t
$$

The spindle used for testing was mounted on a cast iron table with a much larger mass than the tested system. However, in order to check if the resonant frequency of the table is not close to the resonant frequency of the tested system, the amplitude-frequency characteristics of the table were determined first. A B12 sensor from HBM was used for measurements. Using impulse excitation (table excitation was carried out with a hammer), the basic table frequency was determined, which was $10.26 \mathrm{~Hz}$.

The spindle used for the tests was mounted on a cast iron table with a much greater mass than the tested system. However, in order to check whether the natural frequency of the table is not close to the resonant frequency of the tested system, the amplitude-frequency characteristics of the table were first determined. The HBM B12 sensor was used for the measurements. Using the impulse excitation (the excitation of the table was made with a hammer), the fundamental frequency of the table was determined, which was $10.26 \mathrm{~Hz}$. It was defined as the maximum value of the function after the FFT analysis (Fig. 4), The functions available in the Matlab program were used to perform the FFT analysis (Fig. 4). In order to determine the value of the displacement amplitude in physical values $(\mu \mathrm{m})$ for the determined signal sampling frequency (3000 $\mathrm{Hz}$ ), the acceleration sensor was calibrated using a hand-held calibrator. It generated a signal with a known frequency, which allowed for effective validation of the B12 acceleration sensor. Using this type of calibrator, the measuring tools can be fine-tuned to show the standard 1g RMS acceleration level. A reference signal can also be used to calibrate speed and acceleration.

Due to the much smaller dimensions, type 4384 single-axis piezoelectric accelerometers from Brüel\&Kjaer were used to measure spindle vibration. On the basis of the test measurements, it was found that the vibrations in the direction of the excitation force are much larger than in other directions. Therefore, only vibration values 


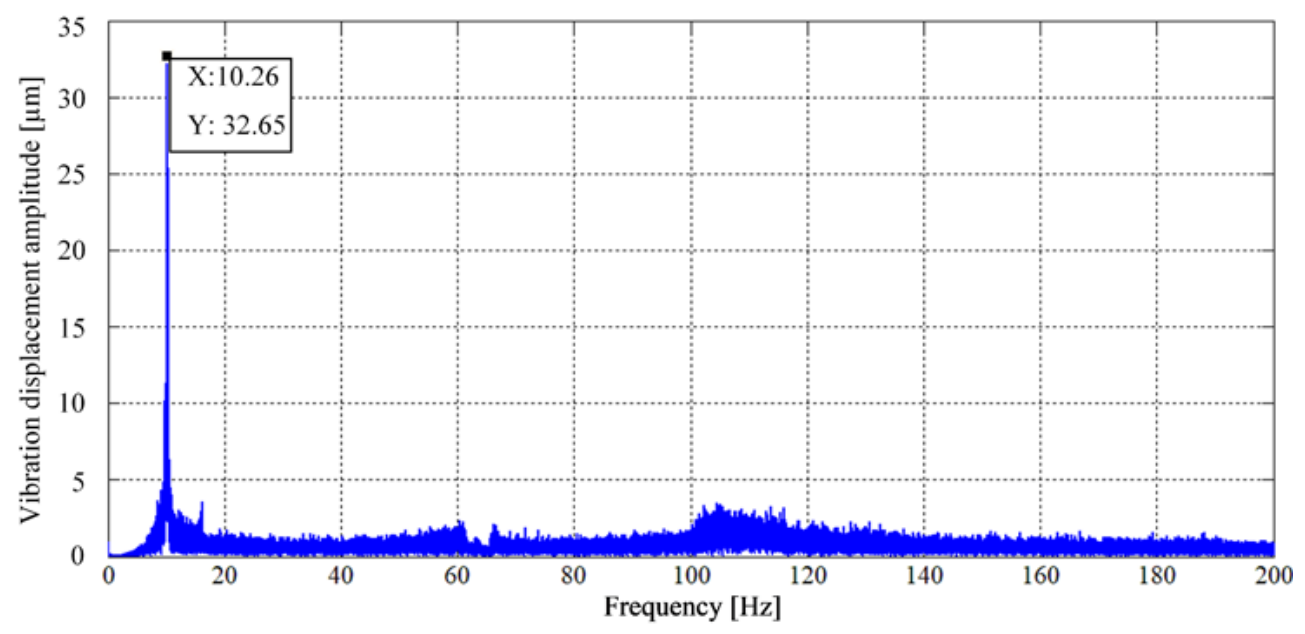

Fig. 4. Amplitude-frequency characteristics of the table on which the tested spindle assembly was placed

in the direction of the excitation force were recorded. The measurement was performed only at three selected points. They were determined according to the diagram (Fig. 5). Their location was dictated by the availability of space on the spindle shaft, which allowed the installation of a measuring sensor. A detailed description of the complete construction is presented in the work [29]. Determination of the amplitude - frequency characteristics was carried out with external spindle drive disconnected.

According to the assumptions of the paper, the tested spindle was to be a grinding spindle (Fig. 6). Hence, a substitute weight weighing about 1.5 $\mathrm{kg}$ (2) was installed at its end, which corresponds to the assumptions adopted in the FEM model. The additional weight at the spindle end causes a change in the amplitude - frequency characteristics of the tested system. Its shape and dimensions were selected so as to allow it to be mounted on the shaft without backlash. In order to cause an excitation of the spindle system, a GW - V20 vibration exciter from Data Physics (1) was used, which was connected to the substitute weight via a cable. The basic parameters of the exciter are listed in Tab. 3. During the excitation, the excitation force signal was monitored by a Brüel\&Kjaer piezoelectric force sensor type 8200 (6). This sensor was mounted on the connection of the exciter cable to the substitute weight.

Linear sweep was used to obtain the amplitude-frequency characteristics. During the sweep, the frequency of the excitation signal increased or decreased in proportion to the time. This signal

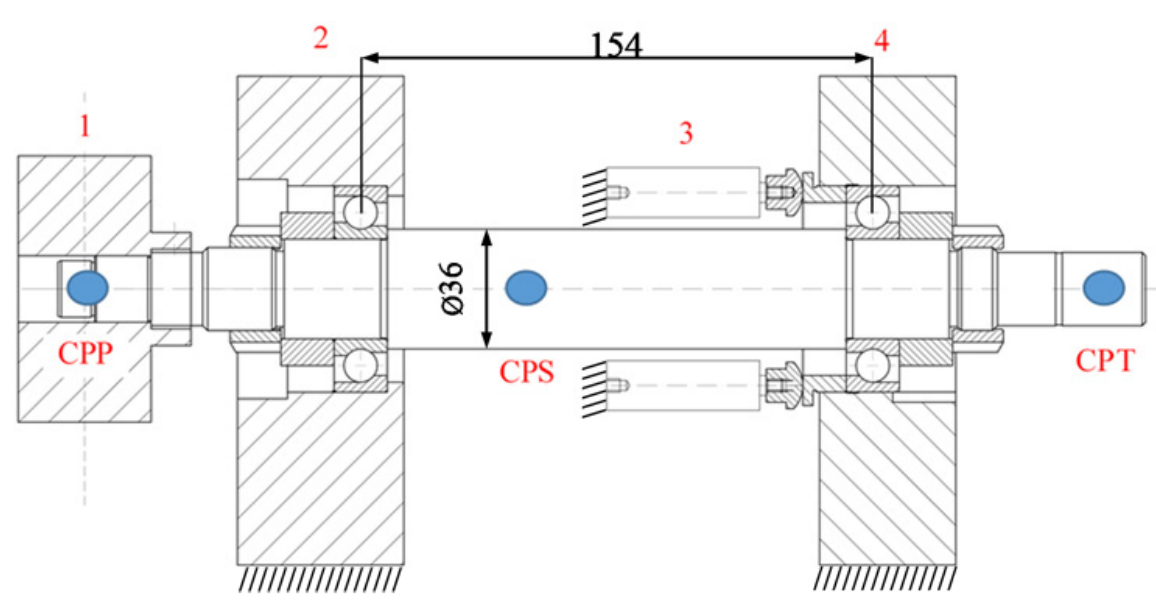

Fig. 5. Arrangement diagram of accelerometers on the spindle shaft, 1 - substitute weight, 2 - front support, 3 - piezo actuators, 4 - rear support, CPP - on the front end of the spindle, CPS - in the middle of the spindle, CPT - at the rear end of the spindle 


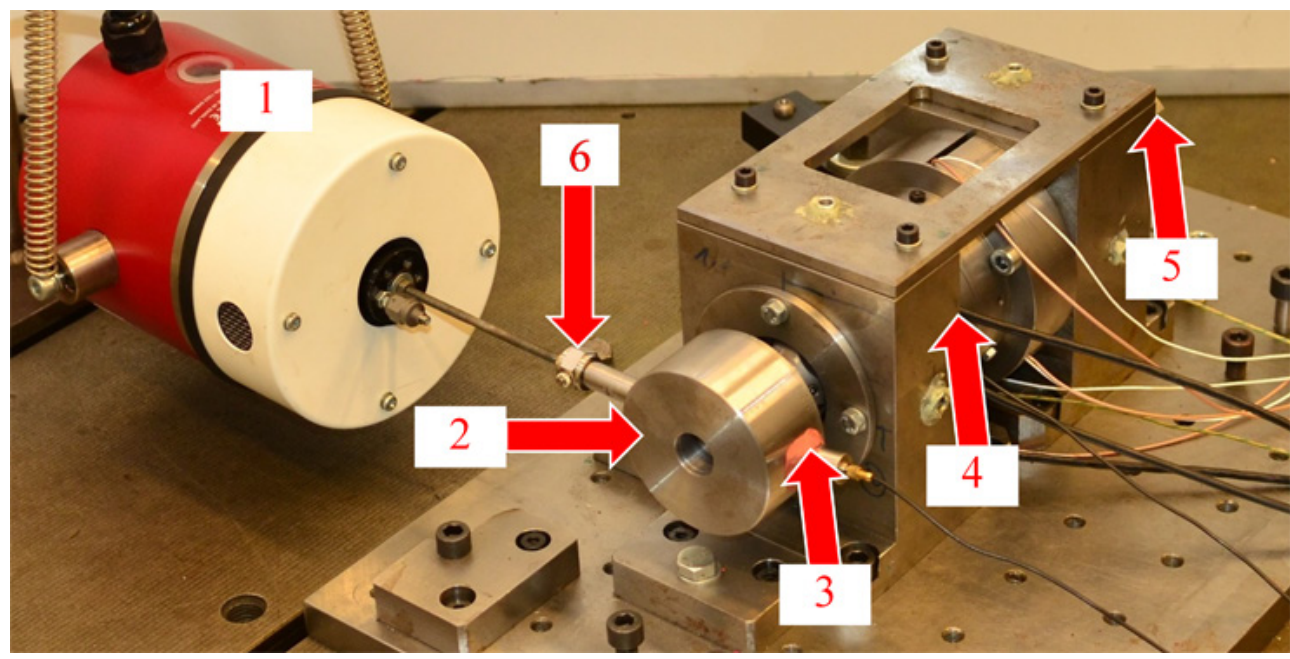

Fig. 6. View of the test setup with the placement of piezoelectric accelerometers and substitute weight at the spindle end: 1 - GW-V20 exciter from Data Physics; 2 - type 4384 substitute weight, piezoelectric accelerometers from Brüel\&Kjaer; 3 - CPP; 4 - CPS; 5 - CPT; 6 - type 8200 piezoelectric force sensor from Brüel\&Kjaer

was fed to the input of the PA 100E vibration exciter amplifier from Data Physics directly from the PC sound card. A sinusoidal random function generator was used to generate the excitation signal. The frequency range in which the system's resonance frequencies occur was determined based on the results of the measurements. Initially, the tests were carried out only for the catalog value of the bearing preload from specifications, which at a later stage of the test was increased and decreased via the piezoelectric actuators used in the system. The preload value was set by using the LabView application on a PC. The signal from the computer was fed to the National Instruments type 9264 measuring card (see Fig. 7). The signal from the card was fed to the input of the piezo actuator amplifier, which set the value of their displacement and the desired preload

After analysing the results for subsequent bearing load states, a logical relationship was

Table 3. Parameters of the electrodynamic exciter

\begin{tabular}{|l|c|}
\hline Exciter model / company & V20/Data Physics \\
\hline Type of amplifier & PA100E \\
\hline $\begin{array}{l}\text { Maximum force for } \\
\text { sinusoidal vibrations [N] }\end{array}$ & 100 \\
\hline Maximum speed [m/s] & 1.51 \\
\hline $\begin{array}{l}\text { Maximum displacement } \\
\text { (stroke) (peak to peak) [mm] }\end{array}$ & 14000 \\
\hline Frequency range [Hz] & $210 \times 178 \times 254$ \\
\hline Dimensions mm [WxDxH] & 16.3 \\
\hline Shaker body weight $[\mathrm{kg}]$ &
\end{tabular}

noticed. With the increase in the supply voltage of piezo actuators, the spindle system stiffness increased, and thus the resonance frequency of the system increased as well. At the same time, there was a decrease in the value of the resonance vibration amplitude. In order to obtain more accurate results and to determine the characteristics of the system more accurately, the frequency range for which sweeping was carried out was narrowed. The range of $150-450 \mathrm{~Hz}$ frequency excitation was determined and the use of harmonic signal was assumed. The sweep time was set to $120 \mathrm{sec}-$ onds and the sampling frequency to $3000 \mathrm{~Hz}$. In order to record measurement data, a specialised National Instruments PXI measuring computer was used, which was equipped with the NI PXI 4472 measuring card.

During the tests, only two type 2635 preamplifiers from Brüel\&Kjaer were available. Therefore, measurements were carried out simultaneously in the front (CPP sensor) and rear of the shaft (CPT sensor). The centre point (CPS sensor) was used only to determine the form of vibration for excitation with a given frequency. Figure 7 shows a complete measuring path.

In order to change the stiffness of the spindle system, the full operating range of piezo actuators was used from -30 to $+150 \mathrm{~V}$ in $30 \mathrm{~V}$ increments. In this way, the following values of the preload force were obtained: $60,90,125,200,280,360$, $430 \mathrm{~N}$. In reference to the measurement path from Figure 8, the measurement cycle was as follows. Initially, using the LabVIEW application and a 


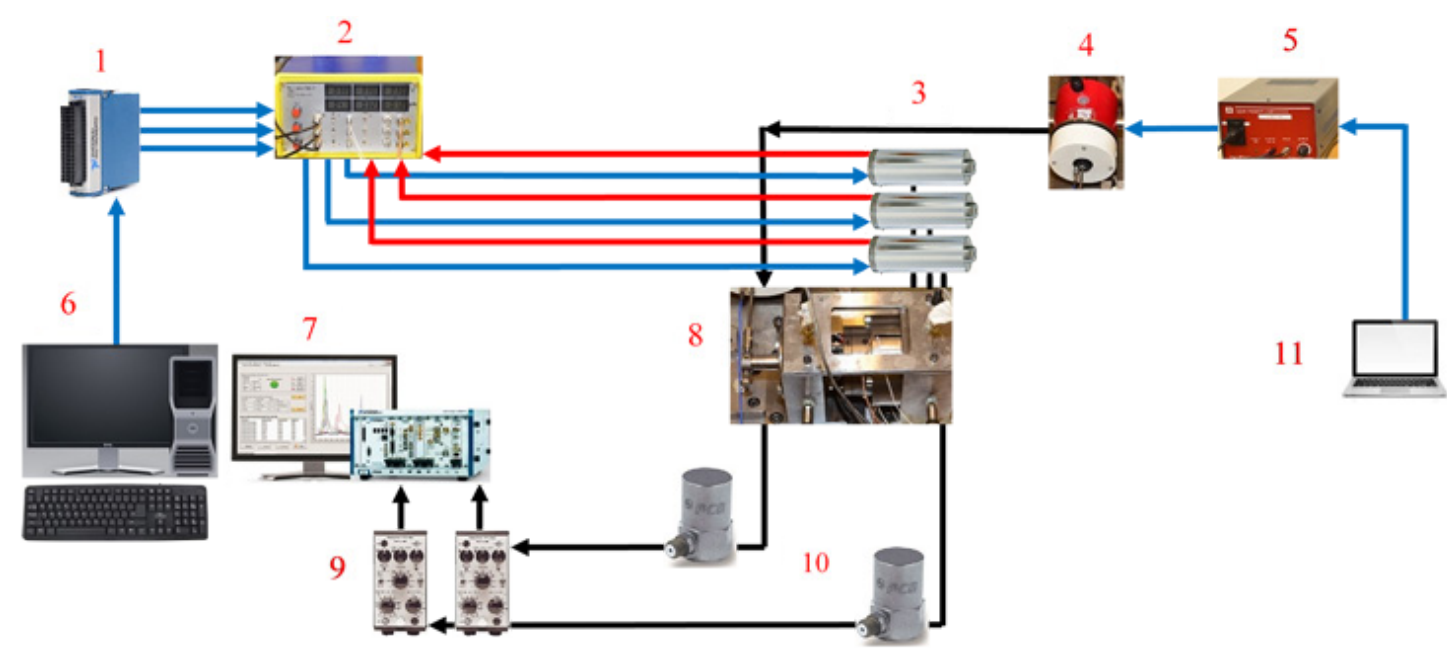

Fig. 7. Diagram of the measurement path for the test setup used for determining the amplitude-frequency characteristics of the spindle shaft at rest with different bearing preload: 1 - type 9264 measurement card from National Instruments, 2 - type SVR 150/3 amplifier for piezo-actuators from Piezomechanik GmbH, 3 - type PSt 150/40/10 piezo-actuators from Piezomechanik GmbH with a built-in strain gauge, 4 - GW V20 type vibration exciter from Data Physics, 5 -vibration amplifier type PA 100E from Data Physics, 6- PC, 7 - specialised

PXI measuring computer from National Instruments, 8 - spindle system tested, 9 - type 2635Brüel\&Kjaer preamplifier, 10 - type 4384single-axis piezoelectric accelerometers from Brüel\&Kjaer, 11 - $\mathrm{PC}$ with a sound card for generating an excitation signal) using the PXI measuring computer and piezoelectric sensors

PC (6), the desired bearing preload force was set. This signal was sent to the measurement card (1), and then to the amplifier (2), which supplied the piezoactuators (3). A second PC (11) was used for system excitation. The excitation signal was generated from the sound card and sent to the amplifier (5) and from it to the exciter (4). The system response was recorded by means of accelerometers (10), from which the signal through preamplifiers (9) went to the PXI computer (7). An example of the characteristics for a selected bearing load state is illustrated in Figure 8 .

The comparison of changes in basic frequencies and resonance amplitudes when changing bearing preload is presented graphically in Figure 9, where the characteristics of changes for subsequent load states of the spindle system can be seen. The error bars are marked in red

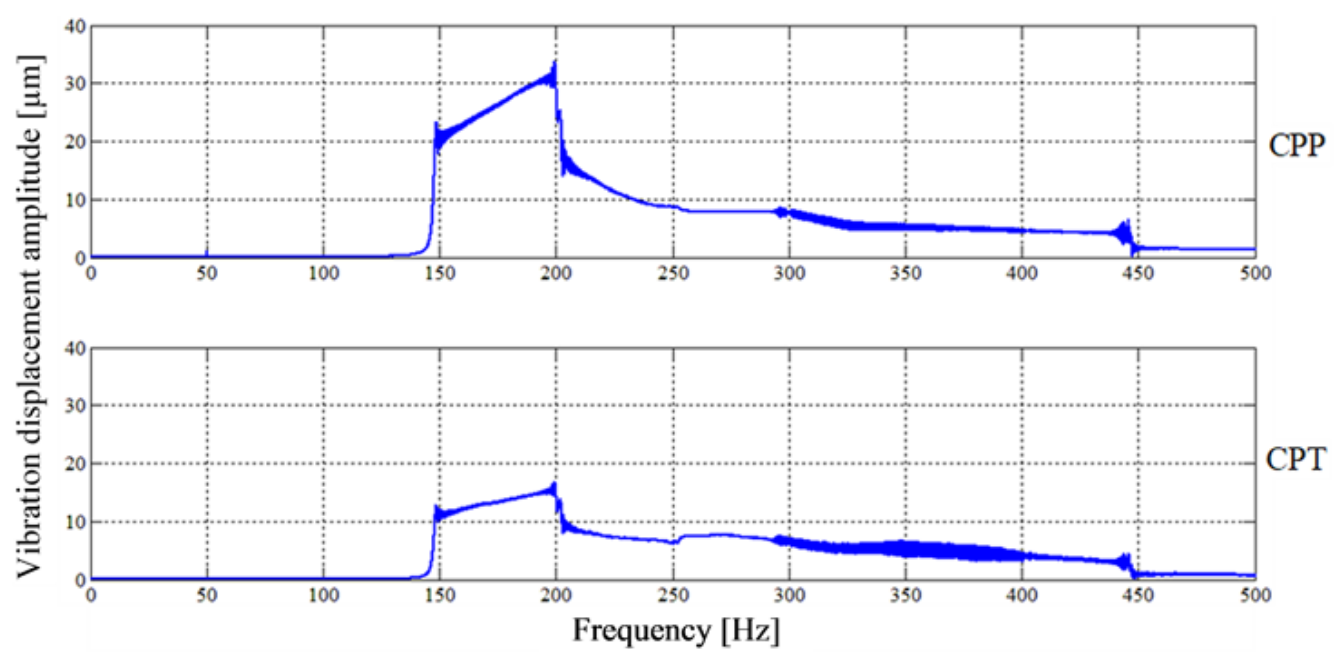

Fig. 8. Amplitude-frequency characteristics of the front and rear spindle end for bearings under $180 \mathrm{~N}$ (60 N per each piezoactuator) determined in the 150 - $450 \mathrm{~Hz}$ range. type 4384Brüel\&Kjaer piezoelectric accelerometer: CPP - at the front end of the spindle, CPT - at the rear end of the spindle 


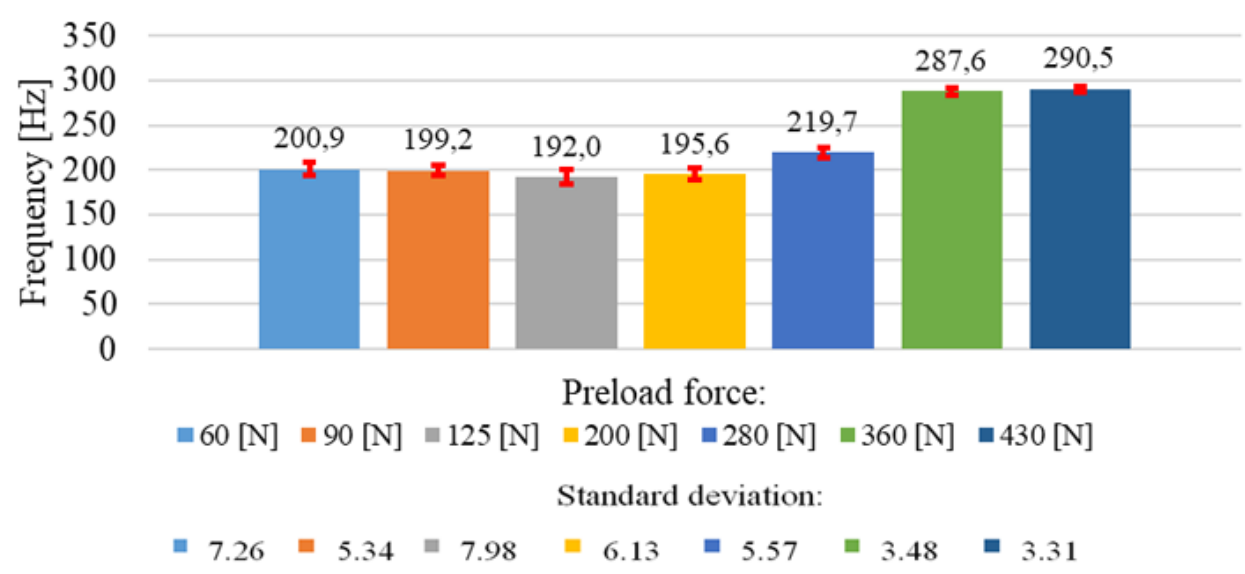

Fig. 9. Graph of the dependence of basic resonance frequencies of the spindle on bearing preload for vibrations in the direction consistent with the direction of the excitation force (mean value, $+/$ - standard deviation $n=5$ )

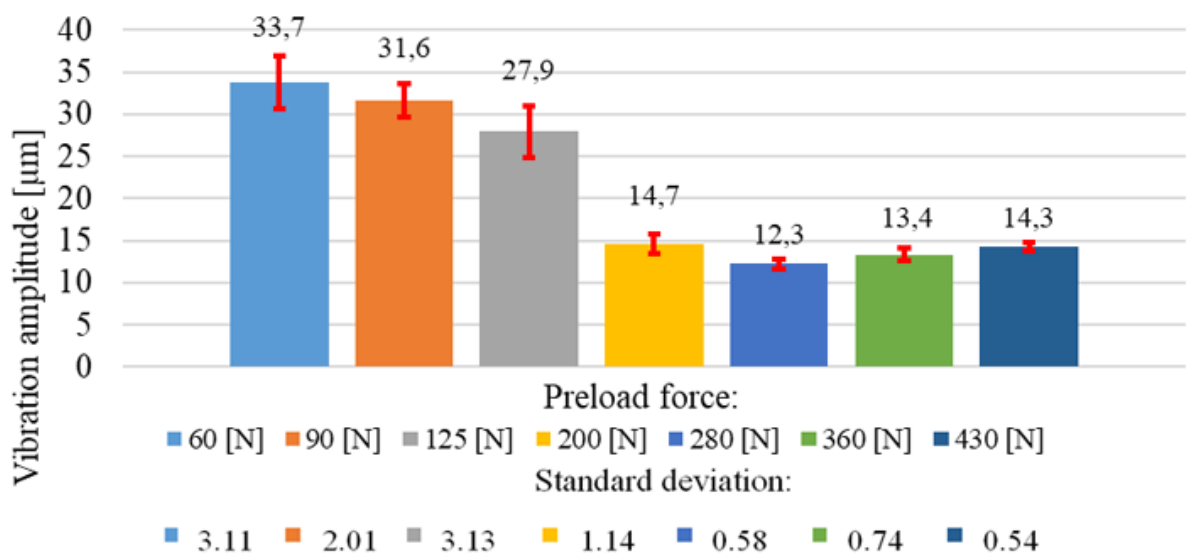

Fig. 10. Graph of the dependence of vibration displacement amplitude for basic resonance frequencies of the spindle on bearing preload for vibrations in the direction of the excitation force (mean value, $+/-$ standard deviation $\mathrm{n}=5$ )

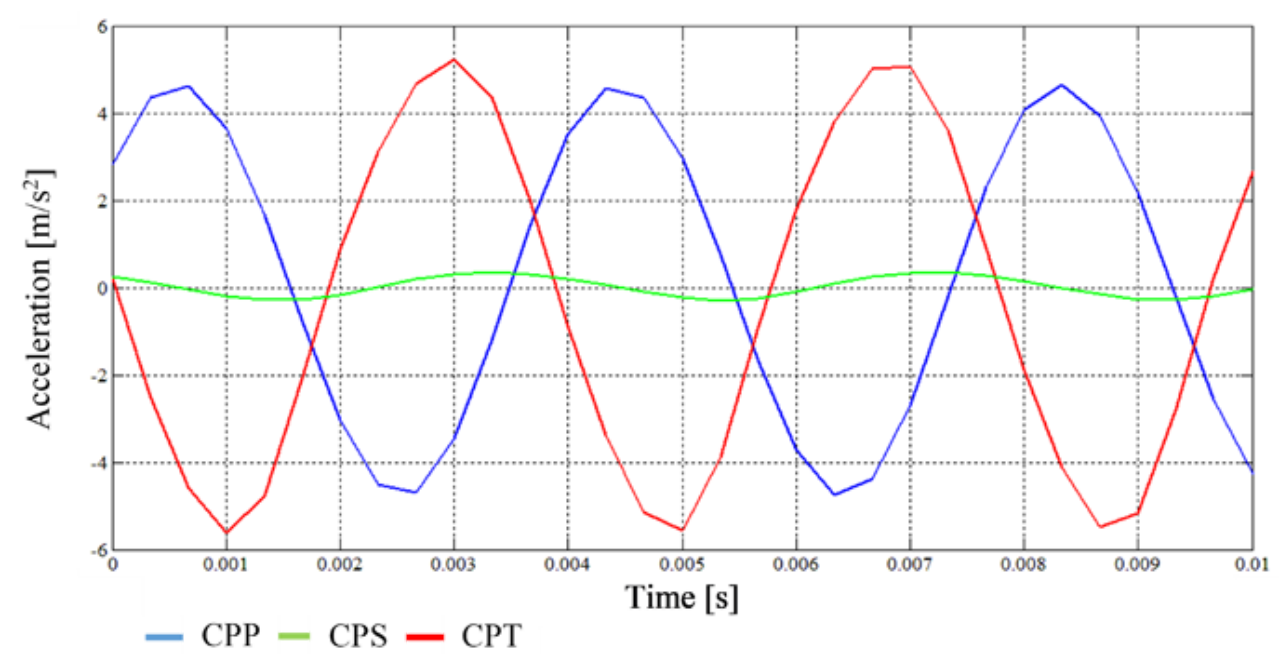

Fig. 11. Sample time graphs of resonance vibrations for three accelerometers located on the spindle shaft (CPP - on the front, CPS - in the middle , CPT - at the rear end) according to the diagram in Fig. 6 (for the preload force of 200N) 


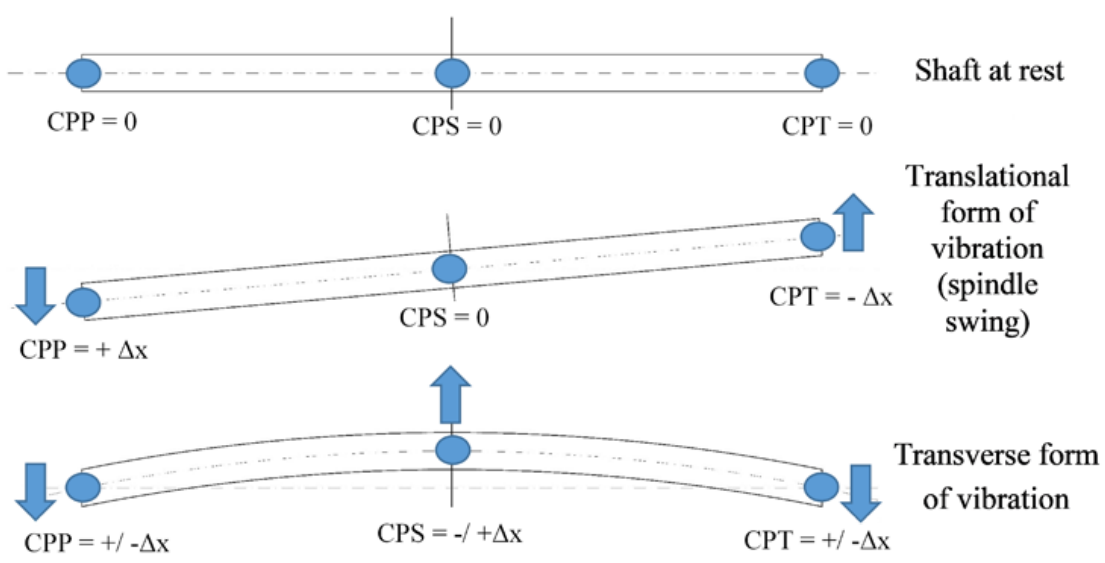

Fig. 12. Diagram of examples of spindle system vibration forms

based on standard deviation from five tests. The comparison was also made for the vibration displacement amplitudes (Fig. 10) corresponding to subsequent frequencies from Figure 9. Error bars are marked in red.

The values of the system's natural frequencies determined in this way were used to confirm the theory based on the FEM model. It assumed that the first of the system's natural frequencies, which shows the highest sensitivity to changing the value of the bearing preload, is associated with the swinging of the shaft on the supports. To this end, re-measurements were carried out at the test setup during which a sinusoidal signal of known frequency (resonant frequency) was determined on the basis of Table 4. Similarly, accelerations were recorded at three points of the shaft according to the diagram in Figure 6. Meratronik G432 function generator was used to generate the resonant frequency signal. It was connected to the exciter's amplifier input and replaced the PC type computer (see Fig. 7, item 11). The result of an example measurement is shown in Figure 11. It presents the time graph for three sensors located on the spindle shaft (See Fig. 5)

The signal values for the CPP and CPT sensor were in counter-phase, which clearly indicated that in the case of the tested spindle the first resonant frequency of the system was responsible for the swinging of the shaft on the supports. The sensor located in the centre of the shaft further confirmed this statement because it showed significantly lower accelerations than in the case of spindle ends. It was located near the centre of rotation of the system relative to which the spindle was swinging. The explanation for this theory is shown in Figure 12.

From Figure 12 it can therefore be concluded that the tested spindle is swinging on the supports. Thus, it is possible to use an active system that will control the value of the preload of the bearings on-line. One of the simpler solutions that can be used to control this system can be based on a typical PID controller (see Fig. 13).

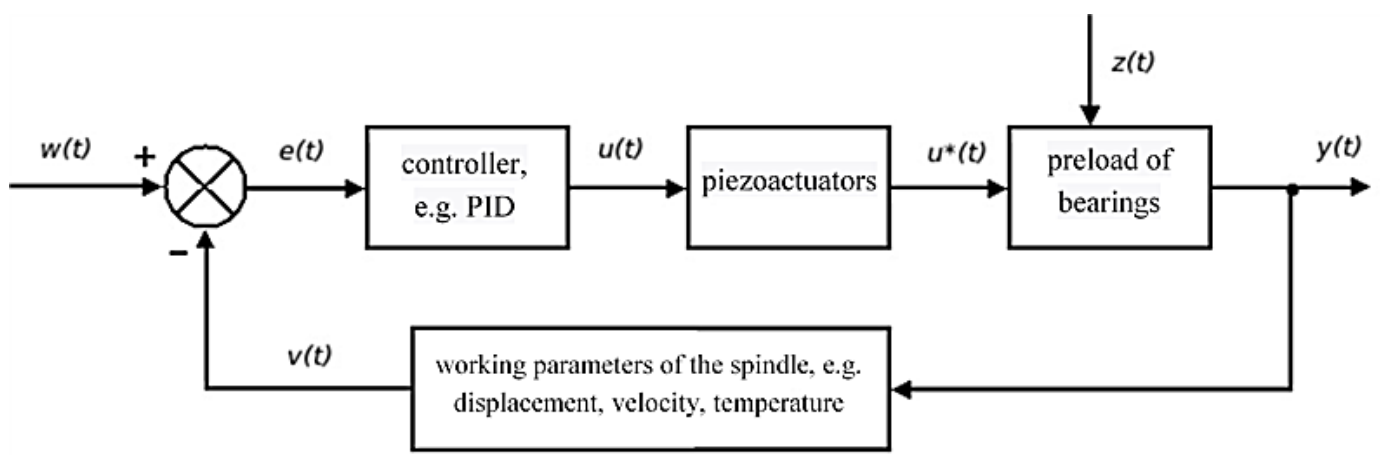

Fig. 13. Example diagram of bearings preload control for a spindle system: w(t) - setpoint value, e $(\mathrm{t})$ - control deviation, $\mathrm{u}(\mathrm{t})$ - control signal, $\mathrm{u}^{*}(\mathrm{t})$ - excitation, $\mathrm{z}(\mathrm{t})$ - interference, $\mathrm{y}(\mathrm{t})$ - output signal, $\mathrm{v}(\mathrm{t})$ - return signal value 
On the basis on the set signal $w(t)$, and control error $\mathrm{e}(\mathrm{t})$, it will control the value of piezo actuator displacement $u(t)$, and thus the preload of the bearings $\mathrm{u}^{*}(\mathrm{t})$. This voltage in the active system is always subjected to interference from $z(t)$, therefore a feedback system is necessary here. The authors plan further research on this system so that it is fully active. In the presented concept, in order to adapt the preload of the bearing to the instantaneous spindle operating conditions and make it dependent, e.g. on rotational speed, bearing operating temperature, and vibration amplitude of the spindle tip, requires continuous measurement of these parameters. The values measured with different sensors will be the value of the feedback signal $v(t)$. Such a solution will be an advantage over the previously used solutions in which researchers focused only on a narrow range of applications for active preload systems of bearings. The basic problem will be the amount of data on the basis of which the control system will be responsible for determining the value of the control signal. In this case, the authors suggest using the digital signal processor - DSP. At the same time, it may be necessary to use high-voltage piezoactuators with higher stability of operation and shorter reaction time for such a problem.

\section{CONCLUSION}

On the basis of the measurements carried out, it can be stated that in the case of spindle systems, a change in the bearing preload affects the frequency and amplitude of mainly the translational forms of vibration (swinging on shaft supports). The FEM model developed shows convergence with the data obtained on the real test setup. The measurements carried out for various bearing load states allow determining resonance frequencies as well as to determine what form of vibrations occurs for the system's natural frequency determined on the basis of FFT analysis. At the same time, analysing the charts in Figs. 9 and 10, it can be seen that the frequency of the system resonance vibrations increases along with the bearing preload. At the same time, the higher the preload, the lower the vibration amplitude is. This type of relationship can therefore also be used to dampen vibrations of the spindle system.

The research results presented in the article allow concluding that it is possible to use piezoelectric elements to change the preload of bearings, as presented by the authors of other publications $[6$, $12,28]$. In comparison, this paper shows that this type of solution can be used to change the dynamic parameters of the spindle. Changing the rigidity of the machine tool spindle through active elements makes it possible to constantly control and correct it. Thus, it is possible to actively influence the level of spindle tip vibration amplitude. The authors showed that by changing the preload of bearings one can only affect the lowest, first form of vibration associated with rocking the spindle. The change in the level of vibration amplitude of the spindle tip during its operation is constantly changing, so that it can be effectively controlled, using the active preload system. Its use, as described in the literature, has a positive effect on the operation of the entire spindle system, bearing life and machining accuracy.

\section{Acknowledgements}

The calculations were made using the resources made available by Wrocławskie Centrum Sieciowo-Superkomputerowe (http://wcss.pl), calculation grant No. 109".

\section{REFERENCES}

1. Alfares, M.A., Elsharkawy, A.A. Effects of axial preloading of angular contact ball bearings on the dynamics of a grinding machine spindle system. Journal of Materials Processing Technology, 136(1-3), 2003, 48-59.

2. Altintas Y., Cao Y. Virtual design and Optimization of machine tool spindles. Annals of the CIRP, 54(1), 2005, 379-382.

3. Cai, J., Jiang, S.Y. Theoretical analysis of preload of high-speed machine spindle bearing. Precision Manufacturing and Automation, 3, 2008, 29-32.

4. Chen J.S., Chen K. W. Bearing load analysis and control of a motorized high speed spindle. International Journal of Machine Tools \& Manufacture, 45, 2005, 1487-1493.

5. Chen, J.S., Hwang, Y.W. Centrifugal force induced dynamics of a motorized high-speed spindle. International Journal of Advanced Manufacturing Technology, 30, 2006, 10-19.

6. Ciou Y.S, Lee C.Y. Controllable preload spindle with a piezoelectric actuator for machine tools. International Journal of Machine Tools and Manufacture, 139, 2019, 60-63.

7. Hadi Hosseinabadi A.H., Altintas Y. Modeling and active damping of structural vibration in machine 
tools. CIRP Journal of Manufacturing Science and Technology, 7, 2014, 246-257.

8. Harris T.A. Rolling bearing analysis (4th Edition). John Wiley and Sons, New York, 2001.

9. Harris T.A., Kotzalas M.N. Rolling Bearing Analysis, Essential Concepts of Bearing Technology. Taylor\&Francis Group, New York, 371, 2007.

10. Hou Y, Wang S, Han Z. The dynamics modelling and simulation for coupled double-rotor spindle system of high speed grinder. Przeglad Elektrotechniczny, 89, 2013, 25-28.

11. Hu, G., Zhang, D., Goa W. Study on variable pressure/position preload spindle bearing system by using piezoelectric actuators under close-loop control. International Journal of Machine Tools and Manufacture 125, 2018, 68-88.

12. Hwang Y. K., Lee Ch. M., 2010, Development of a newly structured variable preload control device for a spindle rolling bearing by using an electromagnet, International Journal of Machine Tools \& Manufacture, 50, 253-259.

13. Hwang, Y. Park, I. Paik, K. Development of a variable preload spindle by using and electromagnetic actuator. International Journal of Precision Engineering and Manufacturing 15(2), 2014, 201-207.

14. Jedrzejewski J., Kwasny W, Kowal Z, Winiarski Z. Development of the Modelling and Numerical Simulation of the Thermal Properties of Machine Tools. Journal of Machine Engineering, 14(3) 2014, 5-20.

15. Jędrzejewski J., Kwasny W. Modelling of angular contact ball bearings and axial displacements for high-speed spindles. CIRP Annals-Manufacturing Technology, 59, 2010, 377-382.

16. Jiang S., Mao H. Investigation of Variable Optimum Preload for a Machine Tool Spindle. International Journal of Machine Tools and Manufacture, 50, 2010, 19-28.

17. Kaczor, J., Raczynski, A. The effect of preload of angular contact ball bearings on durability of bearing system. Proceedings of the Institution of Mechanical Engineers, Part J: Journal of Engineering Tribology, 229, 6, 2015, 723-732.

18. Kosmol J. An extended contact model of the angular bearing, Journal of Theoretical and Applied Mechanics, 57(1), 2019, 59-72.

19. Li H., Shin, Y.C. Integrated dynamic thermo-mechanical modeling of high speed spindles, part 1: Model development. Journal of Manufacturing Science and Engineering, 126(1), 2004, 148-158.

20. Li J.D., Zhu, Y.S., Xiong, Q.Q., Yan, K. Research on axial dynamic stiffness of fixed-pressure spindle. Journal of Xi' an Jiaotong University, 48(10), 2014, 126-130.

21. Li T., Kolar, P., Li, X. et al. Research Development of Preload Technology on Angular Contact
Ball Bearing of High Speed Spindle: A Review. International Journal of Precision Engineering and Manufacturing, 21, 2020, 1163-1185.

22. Lin C. W., Tu J.F. Model-based Design of Motorized Spindle Systems to Improve Dynamic Performance at High Speeds. Journal of Manufacturing Processes, 9, 2007, 94-108.

23. Nye T.W. Active control of bearing preload using piezoelectric translators. Nasa, 1, 1990, 259-271.

24. Parus, A, Chodzko M., Hoffman M. Elimination of self-excited vibrations using an active machining chuck. Modelowanie inzynierskie 42, 2011, 325332, (in Polish).

25. Smolnicki T. Physical aspects of coherence of large roller bearings and deformable support structures. Oficyna wydawnicza Politechniki Wroclawskiej, Wroclaw, 2002, (in Polish).

26. Tönshoff, H.; Denkena, B.; Götz, T. Piezoelectric Actuator Based Preload Control Unit for Machine Tool Spindles. Production Engineering 9, 2002, 117-122.

27. Tu J.F., Stein J.L. Active thermal preload regulation for machine tool spindles with rolling element bearings. Journal of Manufacturing Science and Engineering, 118(4), 1996, 499-505.

28. Turek P., Skoczynski W., Stembalski M. Comparison of methods for adjusting and controlling the preload of angular-contact bearings. Journal of Machine Engineering 16(2), 2016, 71-85.

29. Turek P., Skoczynski W., Stembalski M. Development of fem model of an angular contact ball bearing with its experimental verification. Journal of Machine Engineering 19(4), 2019, 58-69.

30. Wu W., Li X., Xu F., Hong J., Li Y. Investigating effects of non-uniform preload on the thermal characteristics of angular contact ball bearing through simulations. Proceedings of the Institution of Mechanical Engineers Part J-Journal of Engineering Tribology, 228, 2014, 667-681.

31. Xiaohu L., Huanfeng L., Yanfei Z., Jun H. Investigation of non-uniform preload on the static and rotational performances for spindle bearing system. International Journal of Machine Tools and Manufacture, 106, 2016, 11-21.

32. Xu T., Xu G., Zhang Q., Hua C., Tan H., Zhang S., et al. A preload analytical method for ball bearings utilizing bearing skidding criterion. Tribology International, 67, 2013, 44-50.

33. Yang Y., Cai L. G., Zhuo X., Wang Y. D., Liu Z. F. Theoretical research on whirl frequency of high-speed spindle with different preload methods. Journal of Beijing University of Technology, 41(6), 2015, 809-815.

34. Zhang J., Fang B., Zhu Y., Hong J. A comparative study and stiffness analysis of angular contact ball bearing under different preload mechanisms, Mechanism and Machine Theory, 115, 2017, 1-17. 
35. Zhang J., Fang B., Hong J., Zhu Y. Effect of preload on ball-raceway contact state and fatigue life of angular contact ball bearing. Tribology International, 114, 2017, 365-372.

36. Electronic supplies for Piezomechanics: Technical data, Piezomechanik GmbH, katalog produktow, http:/www.piezomechanik.com/fileadmin/filestorage/Kataloge/ en/Electronic_Supplies 2013-12-05.pdf, accessed 26.03.2019.
37. Piezo mechanical and electrostrictive stack and ring actuators: Product Range \& Technical Data - katalog produktow, http://piezomechanik.com/ fileadmin /filestorage /Kataloge/en/ Piezomechanik_Product_range_Low_2017_WEB.pdf, accessed 26.03.2019.

38. Super precision bearings, FAG, MATNR 036884715-0000/SP 1/GB-D/2016061.5/Printed in Germany by Mohn. 